Archivum, LXX (II), 2020, pp. 7-26

\title{
¿Qué significa "escribir en Maryse Condé"?
}

\author{
Martha Asunción Alonso Moreno \\ asuncion.alonso@uah.es
}

Recibido: 09/02/2020

Aceptado: 13/05/2020

\section{RESUMEN:}

Resulta obligado, con el fin de aprehender la especificidad del universo de la narradora guadalupeña Maryse Condé (Pointe-à-Pitre, 1937), abordar el estudio de la lengua propia empleada en sus trabajos. Así parece sugerirlo, de hecho, la propia autora, al repetir incansable en entrevistas concedidas desde los años 80 hasta la actualidad una máxima que ya se ha hecho célebre en el panorama francófono literario: "Ni escribo en francés, ni escribo en criollo: escribo en Maryse Condé" (Pfaff, 2016, 64).

Pero, ¿qué significa, más allá de la exitosa metáfora, "escribir en Maryse Condé"? En un plano primeramente formal, ¿qué caracteriza a esa lengua de creación personal e intransferible? Y, en segundo lugar, ¿qué bagaje político vehiculan esos rasgos lingüísticos únicos? Estas serán las principales preguntas para las que intentaremos ofrecer elementos de eventual respuesta a lo largo del presente artículo.

Con tal fin, acometeremos el estudio empírico de los créolismes condeanos más recurrentes en un corpus de obras representativas de la producción narrativa de Maryse Condé, clasificándolos en categorías semánticas y analizando las implicaciones simbólicas de las mismas.

PALABRAS CLAVE: Antillas. Literaturas francófonas. Narrativa. Guadalupe. Créole. 


\title{
What does it mean "to write in Maryse Condé" ?
}

\begin{abstract}
:
In order to understand the specificity of the narrative universe created by the caribbean writer Maryse Condé (Pointe-à-Pitre, Guadeloupe, 1937), it is necessary to study the personal language used in her works. Condé herself seems to suggest this, by repeating a quote that has already become famous in the francophone literary world: «I do not write in french. I do not write in créole. I just write in Maryse Condé » (Pfaff, 2016, 64).

But what does it mean, beyond the metaphor, "to write in Maryse Condé " ? On a formal level, what characterizes her personal and unique creative language? Is there political baggage hidden on it? These are the main questions for which we will try to offer some answers in this paper.

To this end, we will undertake the empirical study of the most recurrent créolismes used by Condé in a corpus of books representative of her narrative work. We will classify them into semantic categories and we will analyze their simbolic implications.
\end{abstract}

KEY WORDS: West Indies. Francophone Literature. Narrative. Guadeloupe. Créole.

\section{A modo de introducción: del empleo condeano del créole guadalupeño como herramienta de revuelta intelectual}

Hemos centrado nuestro estudio en un corpus formado por títulos tan heterogéneos como representativos de la extensa trayectoria de Maryse Condé. Entre ellos se cuentan novelas, relatos (auto)biográficos y obras destinadas a un público joven. Hemos querido, con esta selección, cubrir todas las etapas y facetas de la producción condeana. He aquí la relación cronológica (junto a cada título figura una clasificación genérica somera):

-Moi, Tituba sorcière, noire de Salem (1986, novela).

-La vie scélérate (1987, novela).

-Haïti chérie (1991, novela juvenil).

-Hugo le Terrible (1991, novela juvenil).

-Les derniers rois mages (1992, novela).

-La colonie du nouveau monde (1993, novela).

-Desirada (1997a, novela). 
-Le cour à rire et à pleurer. Contes vrais de mon enfance (1999, autobiografía).

-Victoire, les saveurs et les mots (biografía, 2006).

-La Belle et la Bête. Une version guadeloupéene (cuento infantil, 2013).

La primera constatación general que se hace evidente, tras una lectura crítica del corpus arriba presentado, es la violenta falla existente entre la lengua del poder metropolitano y la lengua de la lucha anticolonial. Se percibe un abismo entre las dos, que encuentra su reflejo en la convivencia, más o menos tensa, de ambos universos lingüísticos en el habla de sus personajes. Intentaremos a continuación encontrar un paradigma que contribuya a iluminar las implicaciones de los usos entrelazados de una $u$ otra lengua en estas obras.

Para empezar, observamos cómo "el discurso antillano" (Glissant, 1997b), eminentemente oral y local, de personajes como la esclava negra Tituba o la criada mulata Victoire Quidal, contrasta con el francés estándar de sus antagonistas blancos y poderosos. Se erige así en instrumento primordial de una cierta resistencia o revuelta popular ideológica: como herramienta de rebelión, de desafío, de puesta en cuestión y, en definitiva, de "marronnage intellectuel" (Glissant, 1997b, 118). Esto concuerda con la concepción de la noción de francofonía promulgada por Condé: realidad política antes que cultural y, hablando con claridad, mero espejismo, construcción artificial o puro "mito" (Pfaff, 1996, 21) patrocinado por el opresor.

En este orden de ideas, se comprende el esfuerzo e interés político-ideológico de la autora por hacer hablar a sus personajes en créole ${ }^{1}$, lengua popular, de contacto(s) y múltiple por definición. Thérèse Georgel, estudiosa del cuento antillano, nos recuerda sobre esta lengua: "Le créole se parle dans toutes les

1 Nótese que aprobamos y retomamos los planteamientos de Pampín (2011) y Cremades Cano (2014, 62), sobre la práctica imposibilidad de traducción de la "créolité": de ahí que también rechacemos en estas páginas el vocablo "criollo", imbuido de denotaciones hispanas, como equivalente de "créole". 
isles et jusques en Louisiane" $(1999,8)$. El poeta haitiano Monchoachi, por su parte, afirma: “C'est la langue du peuple, créée par le peuple au cours de plusieurs siècles de luttes et de sacrifices" (Monchoachi, 1979, 10). Recordemos además que el créole, en tanto que "idiome nègre", resulta diferente en "presque toutes les îles" (Hearn, 2011, 96).

Otros personajes condeanos, como Marie-Noëlle en Desirada (1997a), establecerán con el créole íntimos lazos de nostalgia. Marie-Noëlle, de regreso a la Guadalupe de su infancia en busca de respuestas sobre la identidad de su padre y su propia identidad, se siente extranjera en su propia lengua materna: "la langue oubliée, celle qui avait donné forme à un monde auquel elle n'appartenait plus" (Condé, 1997b, 148).

También en Desirada, la anciana Claire-Alta, a quien Marie-Noëlle acude en busca de datos sobre el pasado de su madre Reynalda y su abuela Nina, "avait comencé son récit en créole" (Condé, 1999, 160): su lengua materna y, por ello, lengua de la memoria afectiva.

En lo que a Condé respecta, es preciso matizar que, al ser originaria de la alta burguesía negra y afrancesada de Pointe-à-Pitre, nunca pudo sentir esa lengua créole como materna en un sentido al uso. Este dato arroja nuevas posibilidades de lectura a su tan célebre como celebrada frase: "Je n'écris pas en français, je n'écris pas en créole: j'écris en Maryse Condé" (Pfaff, 2015, 203). La autora, en otros contextos, parafrasea dicho enunciado explicando: "Il n'y a pas le français. Il y a le français de Proust, de Chauteaubriand, de Maryse Condé" (Pfaff, 2016, 64).

De esta forma, Maryse Condé niega su identificación con la idea autorial que implica la uniformidad de la francofonía. Se identifica más bien con el cosmopolitismo intercultural, la (in) cierta "identité interculturelle" (Talahite-Moodley, 2007) y la vocación abierta de "Littérature-Monde" (vide manifiesto homónimo de 2007) propios de las literaturas francófonas en general, según viene aceptándose en las últimas décadas. Para dejarlo meridianamente claro, en las nuevas entrevistas con Françoise 
Pfaff publicadas por Karthala en 2016, Condé se complace de nuevo en rechazar enérgicamente incluso la manida y rígida etiqueta de la "créolité" (Pfaff, 2016, 49).

Más allá de la lengua, el sentimiento de pertenencia a un territorio otro, heterogéneo y opuesto a lo metropolitano, se perfila con claridad en el discurso de Condé, cuya militancia independentista conviene recordar a este respecto: "Notre génération a tout fait pour ne pas être française" (Ali Benali y Simasotchi-Bronès, 2009, 64).

Se entiende, así, que asistamos con el paso de los años a una progresiva radicalización en lo que concierne a la convivencia del francés con el créole en los textos condeanos. La autora, no obstante, minimiza con la ironía que la caracteriza su responsabilidad a este respecto, al declarar en las nuevas conversaciones con Pfaff datadas en 2016: “C'est l'éditeur [...]. Si c'est la théorie de l'éditeur qu'il faut un glossaire, bon, j'en fait un" (Pfaff, 2016, 133).

En Tituba (Condé, 1986), por ejemplo, la esclava protagonista y las mujeres de los cimarrones de Barbados emplean con frecuencia, haciendo gala de "cette fierté Marron" $(1997,148)$ que las caracteriza, palabras en la lengua de su isla. Ya en la edición original, sus vocablos se traducían al francés mediante notas a pie de página. A saber: "Pardonne-leur, ce sont des guerriers, pas des grangreks*" (Condé, 2006, 223).

A propósito del juego con los créolismes y sus traducciones francesas (o bien su ausencia deliberada), no podemos dejar pasar el notable caso de La vie scélérate (1987), novela con la que el universo narrativo de Condé regresa al espacio guadalupeño natal. Es en este libro, a nuestro modo de ver y leer, donde las implicaciones políticas del plurilingüismo literario voluntario en Condé comienzan a explicitarse y afirmarse con mayor rotundidad, superando los corsés (post)coloniales y delimitando la originalidad de la lengua propia de creación. Retomando los términos de André Jacques en su libro Caraïbales, études sur la littérature antillaise, constatamos en Condé un frecuente discurso "rapporté ou transcrit en français patoisé". Eso desemboca en 
una personalísima escritura, situada en los estratégicos espacios de "frottement des deux langues" (André, 1981, 16).

En esa frontera, hacen su aparición términos créoles que, hacia el inicio de la novela, el lector deduce que encontrará traducidos por sistema en las consabidas notas al pie. A saber: "moudongue / moundongue / mondingue / soubarou" (Condé, 1987, $23)^{2}$. Nada más lejos de la realidad, sin embargo. Poco después, todavía en la primera parte de la novela, la autora empieza a sembrar indicios de duda y desconcierto: en una misma página, traduce el término "morne" y deja sin traducir, sorprendentemente, la expresión "coqs guimb". Tiene lugar este lapsus voluntario, si se nos permite la licencia, en un pasaje en absoluto casual: una metafórica reflexión en voz alta del héroe, Albert, acerca de la condición negra. El protagonista le explica a su madre, la anciana Théodora, que, más allá de la inmensa diversidad lingüística real, todos los hombres negros comparten el idioma fraterno de la miseria:

Maman, là-bas, j'ai rencontré des nègres qui parlent anglais qui parlent portugais, qui parlent hollandais! Mais la langue commune, maman, c'est la misère! (Condé, 1987, 35).

Muy parecida aseveración (se trata, en verdad, de un proverbio créole) puede leerse en Haïti chérie: “Moi, la deveine, c'est mon frère. D'ailleurs, est-ce que ce n'est pas le frère de tous les nègres ?" (Condé, 1991, 71). También en Le récit de Movar, en la novela En attendant la montée des eaux, leemos: "La misère n'est pas douce. Lan mizè pa dou" (Condé, 2010, 43).

Todos estos giros créoles incorporados al relato condeano no deben considerarse, en nuestra opinión, como meros elementos ornamentales orientados a la configuración de un escenario vibrante de exotismo, sino como la expresión de una auténtica "culture de la résistence", retomando los términos Chantal Maignan-Claverie

2 "Salvaje", en criollo de Guadalupe. 
sobre la escritura de la también guadalupeña Simone Schwarz-Bart $(2005,403)$ en su novela Pluie et vent sur Télumée Miracle (1972).

Les derniers rois mages (Condé, 1992), se abre con un Glossaire des principaux mots (10) que puede recordar al glosario de "expressions et vocabulaire antillais" que Françoise Ega ya incluyó como cierre de Le Temps des madras en la década de los años 60 (Ega, 1989, 177-180). Nuevamente, pronto el lector se dará cuenta, con comprensible desconcierto, de que los dieciséis términos ahí recogidos no son en absoluto todos los que aparecen en la novela.

En La Colonie du nouveau monde (Condé, 1993), apenas un año después, se traducen con asteriscos muchas voces a pie de página, especialmente términos del vudú (Condé, 1993, 82: "poto-mi$\tan ^{* \prime)}$ o ciertas palabras españolas (Condé, 1993, 83, "cachaco*: habitante de Bogotá"). Mas, una vez más, la autora nos reserva motivos para el desconcierto: muchos otros términos en español, lejos de traducirse, se emplean con más o menos naturalidad (en ocasiones, se escriben en cursiva, pero no siempre): "calle" (Condé, 1993, 28 y ss.), “burundanga” y "ciénaga” (Condé, 1993, 199), "mondongo" (Condé, 1993, 204 y ss.), "manjar blanco" (Condé, 1993, 207), "malecón" (Condé, 1993, 251)...

Este modo de proceder nos hace pensar en Gouverneurs de la rosée, novela cumbre de la literatura haitiana, por Jacques Roumain, citada especialmente por Condé en Le Cœur à rire et à pleurer (Condé, 1999, 117), La Belle et la Bête, une version guadeloupéenne (Condé, 2013, 30) y En attendant la montée des eaux (Condé, 2010, 20 y ss.). En el libro de Roumain, muchos créolismes -palabras, expresiones, proverbios o letras de cantos- se traducen someramente a pie de página. Sin embargo, permanecen sin definir, aunque marcados en cursiva, bastantes términos caribeños hispanos, que el héroe de la novela (Manuel) ha incorporado a su habla tras pasar quince años trabajando duramente en los campos de caña cubanos.

En Desirada (Condé, 1997a), se perpetúa este enfoque lúdico e irónico: se señalan en cursiva muchas frases o términos, pero no por ello se traducen. Por ejemplo, los platos "bacalao" y "frijoles 
negros" (Condé, 1997a, 123), que testimonian, por otra parte, de la gran cultura gastronómica de la autora.

En Haïti Chérie (Condé, 1991), los créolismes y ciertas referencias culturales o históricas antillanas bien concretas, se indican nuevamente con asteriscos y se desarrollan a pie de página. Lo mismo ocurre con el libro, también juvenil, La Belle et la Bête, une version guadeloupéenne (Condé, 2013). Por otra parte, en el primer libro, hay ciertos diálogos en créole, que sin embargo se reproducen únicamente en francés (Condé, 1991, 70), a excepción de la letra de la tonada popular Haïti chérie, citada en haitiano y versionada a pie de página (Condé, 1991, 71). Resulta comprensible dado el público infantil y juvenil del libro, por una parte; y dada la intención didáctica tanto de la colección como de la publicación, por otra. Este carácter pedagógico, en el caso del segundo libro, queda más claro si cabe: el texto viene acompañado por un dossier pedagógico destinado a guiar y facilitar la explotación del mismo en el aula por parte de profesores con sus alumnos. Por otra parte, el texto fue publicado en la editorial Larousse, de marcada vocación didáctica, en una colección de clásicos y textos escogidos para la juventud.

En el mismo año de la aparición de Haïti chérie, 1991, en otra novelita destinada al público juvenil, hallamos un procedimiento similar: Hugo le Terrible se abre con una somera indicación que reenvía a sus jóvenes lectores al "petit glossaire" final. Este incluye once respectivas explicaciones de créolismes en términos bien simples.

Dieciocho años después, en Le Cour à rire et à pleurer (Condé, 1999), los créolismes (guadalupeños, en este caso) destacarán por una recurrencia aún mayor. Para comprender su significado, el lector alófono deberá tomarse el tiempo de buscarlos en el glosario que cierra la edición. Las claves de comprensión, así, ya no se encuentran en su contexto, al alcance inmediato de la mirada; y el mencionado lector alófono acusará en mayor medida el hándicap de su monolingüismo.

Llegaremos así a los títulos La Belle Créole (Condé, 2001) y a Victoire, les saveurs et les mots (Condé, 2006), donde no transcurre 
una página sin créolismes de todo tipo: no sólo palabras concretas, sino también canciones populares o comptines, nanas, cuentos, adivinanzas, recetas, sortilegios, refranes, etc. A menudo, estos créolismes proporcionan información capital para el relato. Así ocurría en el librito juvenil Hugo le Terrible (Condé, 1991), que incluía y traducía, con claro afán didáctico, el refrán "Kan gwan moun ka palé, ti moun ka pwyé dié" (Condé, 1991, 9), es decir, "Quand les grandes personnes parlent, les enfants prient le Bon Dieu” (Condé, 1991, 128). Sin embargo, ningún refrán, giro idiomático o proverbio se traduce en las novelas para adultos arriba mencionadas: "-Corossol doudou, crie une marchande instalée au carrefour" (Condé, 2006, 169); "Fwansé foukan" (Condé, 1989, 43 y ss.; Condé, 2001, 17: “Français, foutez le camp !").

Esta cohabitación cada vez más espontánea de las lenguas populares negras (ligadas al contrapoder) con la elitista lengua blanca (vehículo del poder opresivo) en las novelas de Condé, a nuestro parecer, se relaciona íntimamente con una de las nociones clave de la Negritud, la Antillanidad y la Creolidad según Jean Bernabé, Patrick Chamoiseau y Raphaël Confiant: la literatura de tradición oral u "oralitura" (Bernabé et alii, 1993, 153-171).

Dicha tradición oral, según Condé, se construye sobre la multiplicidad de la diferencia, siempre patente en su trabajo y su pensamiento como política, que adquieren así claras dimensiones etnológicas y etnográficas:

L'oralité et l'écriture sont étroitement mêlées, chacune tentant d'imposer sa marque. Quant à moi j'ai besoin de musique pour écrire et je suis vivement intéressée par toutes les formes de musique. Cela revient à dire que je ne me situe pas très loin de l'oralité (Condé, 2015, 215).

La literatura condeana, en virtud de sus lazos estrechos con la oralidad, se caracteriza, como la oralidad misma, por la hibridación y la heterogeneidad de referentes, idiomas, ritmos y afectos de cada eslabón humano transmisor de cierto bagaje colectivo. Para Maryse Condé, además, la lengua criolla supondría antes 
una elección militante -una consecuencia de su "cœur à gauche" (Condé, 2010, 39) y de su adhesión, al menos teórica e idealmente, a los preceptos del marxismo ${ }^{3}$ - que la pasividad de una herencia.

$\mathrm{Su}$ progresiva introducción en su escritura nos parece responder, así, a una voluntad transgresora de "repenser le militantisme" desde múltiples ópticas (Pfaff, 2016, 24), por un lado; y a una toma de conciencia de la necesidad de denunciar los estragos colonialistas a nivel humano, ligada a un voluntarioso ejercicio de reivindicativa libertad, por otro lado. Estamos, pues, ante un posicionamiento poético de motivación política:

Disons seulement que tout est différent en fonction de chaque individu. Chacun d'entre nous a un rapport différent avec le français comme avec le créole. Sans mépris, sans aliénation, je répète que le créole ne peut pas faire figure de langue maternelle. Ma langue maternelle, que ma mère me parlait, a été le français, avec tout ce que ça sous-entend peut-être comme frustrations et comme manques (Ali Benali, 2009, 3).

La postura de Condé, en suma, comulga con el análisis y las experiencias que de la identidad caribeña han realizado y relatado autores como su compatriota y amigo el poeta Daniel Maximin, para quien las culturas caribeñas se encuentran caracterizadas, esencialmente, "par le refus de tout encerclement, de toute injonction esthétique ou idéologique, autre que l'exigence de liberté" (Maximin, 2006, 17).

\section{Estudio empírico de los créolismes condeanos}

Es posible rastrear un total de trescientos créolismes (Alonso Moreno, 2018) empleados por la autora en las novelas de nuestro corpus. Por motivos formales, no incluiremos aquí el glosario desarrollado con las trescientas entradas. Nos limitaremos a su enunciación y categorización, definiendo con mayor detalle una o dos ocurrencias significativas de cada subgrupo.

3 “...mes nouveaux amis me 'politisèrent' [...]. Si je devains marxiste, c'est-àleur contact, plus que par cheminement personnel" (Condé, 2012, 88). 
Es preciso aclarar que nuestro estudio ha considerado vocablos y expresiones propios de las lenguas y realidades criollas de Guadalupe, Martinica, Barbados, Jamaica, Haití y otras regiones del Caribe (bien diferenciadas entre sí, pues es sabido que no existe un único créole). Contempla asimismo un menor número de africanismos, localizados sobre todo en las novelas de ambientación africana de Condé, aunque no sólo. Esos africanismos configuran el universo créole condeano, caracterizado por el nomadismo y por lo heteróclito (la criollidad entendida como matriz creativa de hibridación es, de hecho, la base del pensamiento condeano). Hablamos así de un universo hondamente antillano, animado por una clara voluntad de memoria de los crímenes de la esclavitud y de la trata de seres humanos arrancados de su África natal. Se entiende, por tanto, que ciertos africanismos formen parte del acervo lingüístico de personajes caribeños, hijos desarraigados un África mítica precolonial; y que se incluyan aquí. El mismo razonamiento se aplica a los términos de regiones antillanas anglófonas contemplados.

Por añadidura, hemos considerado pertinente incluir ciertos vocablos franceses que, sin ser créoles desde el punto de vista morfológico, se caracterizan por su uso local: describen realidades marcadamente caribeñas o de ultramar, cuya comprensión resulta fundamental para integrar la especificidad de la obra de nuestra autora.

Además de recurrir en ocasiones a fuentes orales directas y basarnos en nuestra experiencia vital personal en la isla de Guadalupe, nos hemos servido en esta labor de la prensa y los medios locales, de estudios sobre la flora (ONU, 1982) y de obras clave de la lexicografía del Caribe francófono. Ocupan un lugar prominente entre estas últimas los trabajos, ya clásicos y pioneros, de Chaudenson (1979), Barbotin \& Tourneaux (1990), Romaine (1993), Barbotin (1994 y 2009), Bélaise (2006) o Pinalie (1994 y 2009).

Para identificar los términos culinarios, principalmente hemos recurrido al estudio sobre las delicias y virtudes de la cocina antillana y guyanesa tradicionales del Doctor Nègre (1985); a los 
recetarios de Ary Ebroin (1977) o de Hearn (2011 [1885]), a fuentes orales y a nuestra experiencia.

Es preciso señalar que, a menudo, el lector encontrará diferentes propuestas de grafías. Esto responde a las dificultades que conlleva el "passage du créole de la langue parlée à la langue écrite" (Monchoachi, 1979, 10) que, en los años 80 del pasado siglo, "ne s'est pas encore opéré" (idem). Desde la década de los 70, autores como Dany Bebel-Gisel, autor de Kék prinsip pou ékri Kreyol (1978), llevan intentando sistematizar el problema. Tres décadas después, esta transición continúa gestándose; y consideramos lícito afirmar que la obra condeana ha contribuido notablemente a los sólidos progresos experimentados por el créole en su devenir literario desde entonces. Queda, no obstante, harto camino por recorrer en este paso "d'un savoir pratique à un savoir théorique" (Monchoachi, 1979, 11), que inevitablemente implica una profunda lucha entre poderes por los poderes.

Queremos señalar, por otro lado, que hemos procedido a la clasificación en diferentes categorías semánticas y, en ocasiones, gramaticales de todos los términos recogidos. Estas categorías suman veintitrés en total. Se siguen numeradas de mayor a menor en orden de recurrencia:

1) Comida y bebida (63 ocurrencias).

2) Flora (56).

3) Fraseologismos y lengua (32).

4) Mujer (27).

5) Fauna (21).

6) Música, bailes e instrumentos (20).

7) Religiosidad, magia y supersticiones (23).

8) Fiestas, tradiciones, usos y costumbres (17).

9) Color de piel (16).

10) Clase social (16).

11) Oficios (16).

12) Hombre (14).

13) Insultos, maldiciones y juramentos (14).

14) Remedios naturales (13). 
15) Mitos, cuentos y leyendas (11).

16) Historia y política (11).

17) Vestuario y accesorios (8).

18) Infancia (8).

19) Amor (8).

20) Hogar y objetos domésticos (7).

21) Onomatopeyas (4).

22) Orografía, clima y paisaje (4).

23) Otros (8).

Llegados a este punto, es preciso realizar una aclaración: raros son los términos exentos de pertenecer, según contextos, a dos o más categorías; lo cual ofrece una primera evidencia de la riqueza del léxico créole, traducción a su vez de la inmensa riqueza de su medio natural, cultural y social.

El análisis de cada una de estas categorías semánticas en el corpus revela, como bien puede verse de manera gráfica en el diagrama de barras que incluimos más abajo (en horizontal, las 23 categorías; en vertical, sus ocurrencias), el alto valor sociológico de la obra de Maryse Condé en tanto que testimonio de un cierto estilo créole de vida. Y viceversa: la importancia arterial de la creolidad, en toda su poeticidad y también en su dimensión política, en la constitución del universo narrativo condeano.

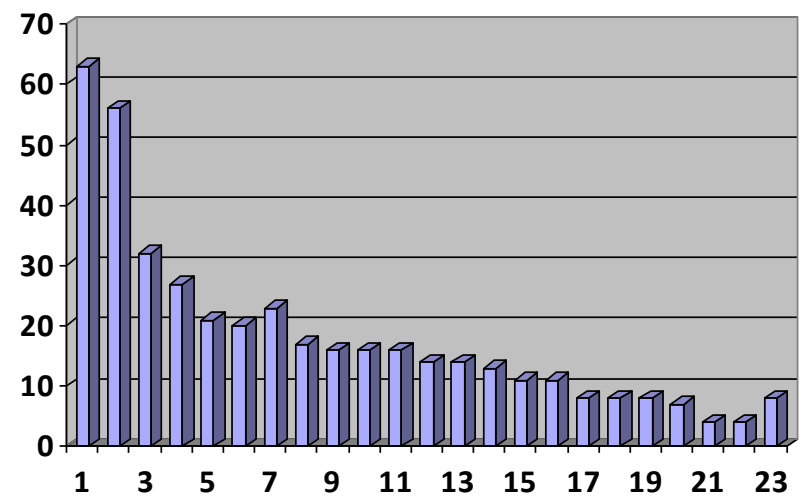

Fig. 1.: las 23 categorías semánticas de créolismes condeanos y sus ocurrencias. 
No sorprende que los créolismes más empleados resulten ser aquellos que traducen el carácter autóctono de la gastronomía o del "mangé-Créole" (Hearn, 2011, 356) y del hábitat natural créole, muy concretamente, de la flora autóctona (categorías 1 y 2, con 63 y 56 ocurrencias respectivamente). En efecto, la exaltación sensorial de los placeres proporcionados por la buena mesa y la reivindicación de lo culinario en tanto que saber artístico femenino constituyen rasgos comunes de todas las novelas de nuestra autora (Victoire, sobre todo).

En esta categoría destacan términos como "chiktay / chiktaye / chiquetaille (de morue)", que aluden a un célebre plato antillano a base de migas de bacalao especiadas y con vegetales. Puede servirse frío, a modo de entrante, o bien caliente (Condé, 1987, 270; Condé, 1992, 251). Es posible escuchar el verbo derivado: "chictailler", es decir, "desmigar, desmenuzar" (Condé, 1987, 111). Es el caso en este pasaje de La Vie scélérate donde Elaïse y Liza continúan, incluso después de muertas, ocupándose de cocinar para Albert, su amante y esposo respectivamente:

Mortes, Elaïse et Liza se firent la paix et s'accodèrent pour tenir le ménage de leur Albert [...]. Puis elles faisaient couler du café dans une vieille cafetière d'émail bleu, réchauffaient les cassaves qu'il gardait dans une boîte à biscuits et chictaillaient du hareng saur (Condé, 1987, 111).

Nos reenvía dicha categoría al universo de los trabajos y de los saberes femeninos desprestigiados desde la óptica patriarcal. Nos revela asimismo la importancia en la narrativa condeana del elemento sensorial y primario -en su acepción más positiva- como elemento desencadenante de la epifanía gastronómica $\mathrm{y}$, al más puro estilo proustiano, de la recuperación del tiempo perdido.

En estrecha relación con la gastronomía y el hábitat natural créoles, figuran, lógicamente, los créolismes relacionados con la flora autóctona y, por ende, la medicina natural o los remedios caseros: de nuevo, lo culinario. Toda fruta o planta, en las regio- 
nes antillanas, tiene una aplicación cosmética, medicinal o gastronómica.

Destacaremos las menciones a árboles locales como el denominado «arbre du voyageur», de origen asiático, de la familia de las palmeras. Alcanza grandes alturas y se distingue por su ramaje inconfundible, en forma de abanico, que guarda sempiternamente agua entre sus ramas. De ahí su nombre: el viajero siempre podrá aplacar su sed en él (Condé, 2003, 52).

Por poner otro ejemplo, abundan las alusiones, por parte de personajes mujeres, a la "assa fœtida / asa fœetida" o la "asafétida", en español. Se trata de una hierba con flor amarilla y olor desagradable, con propiedades terapéuticas (se asocia a los tratamientos de la histeria femenina) y culinarias (se emplea mucho como condimento y colorante). Por su olor, se la denomina en ocasiones "merde du diable", "herbe du diable", "estiércol del diablo" ... (Condé, 1987, 313; Condé, 1995, 134; Condé, 1999, 22).

La importancia de estos términos viene a confirmar nuestra visión de la obra condeana en tanto que puesta en valor, entre otras cosas, de los saberes originariamente femeninos. Los saberes relativos al control y a los cuidados del cuerpo, propio y ajeno, forman parte del mismo capital cultural en femenino que el nutricio saber culinario. Estos conocimientos configuran a ojos patriarcales y a lo largo de los siglos la distorsionada imagen de la temida mujer-bruja (vide Federici, 2004). Una imagen que se explica, a fin de cuentas, por el temor ancestral a la inquietante liberación latente en la sabiduría femenina.

En este orden de cosas, no nos resistimos a considerar la siguiente categoría semántica de créolismes condeanos más frecuente (la de los fraseologismos: fundamentalmente, proverbios, refranes y demás expresiones lingüísticas idiomáticas de compleja traducción) en tanto que una característica más de dicha arquetípica mujer-bruja. Las paremias créoles, en boca de los muy sabios personajes femeninos condeanos, adquieren resonancia de conjuro mágico: vehiculan una honda sabiduría, comúnmente calificada de popular y dotada de un ritmo atemporal. 
Sin duda, el proverbio más repetido es "Fanm tonbé pa janmin / janmé dézespéwé / dézespéré", esto es, "Femme tombée ne désespère jamais / Femme tombée pas jamais désespéreée" (Condé, 1989, 183; Condé, 1993, 53; Condé, 2003, 348). En La colonie du nouveau monde, lo traduce a pie de página por: “Une femme ne doit jamais perdre espoir !" (Condé, 1993, 53); y en su ensayo La parole des femmes como "Une femme tombée se relèvera toujours" (Condé, 1993, 4). La imagen de la mujer caída mas nunca vencida conecta además, en el imaginario condeano, con la de la castaña de Indias madura que germina una vez en el suelo (Condé, 1993, 4).

La estadística, a este respecto, parece sustentar esta idea. Tras los fraseologismos, encontramos los créolismes condeanos que reenvían a la mujer. No es posible obviar la importancia del vocablo "potomitan / poto-mitan / poteau-mitan", esto es, "poteau central". Se emplea para definir al arquetipo de mujer antillana ideal, aún hoy en día: mujer que cimienta y sostiene el edificio familiar, matriarca (Condé, 1987, 145; Condé, 1993, 82; Condé, 1997a, 190; Condé, 2001, 86; Condé, 2006, 229; Condé, 2010, 81), base del modelo familiar matrifocal.

El origen del término ser relaciona metonímica y analógicamente con una realidad arquitectural fundamental de los templos vudúes de Haití, llamados "oufo / hornfour / homfort" (Condé, 1993, 181): la columna central de los mismos, en torno a la cual se organiza el culto y se disponen tanto los fieles potencialmente poseídos como los "loas" o espíritus poseedores (Condé, 1991, 13).

A los términos relacionados con la mujer, les siguen los relativos a la fauna, la música, los bailes e instrumentos; la religiosidad, la magia y las supersticiones ("l'invisible", en términos de Pagán López, 2004); las tradiciones, los usos y las costumbres. El complejo mundo de la sabia créole, en todas sus facetas, queda, en fin, declinado en su riqueza y sutilezas a través de estas recurrentes categorías semánticas simbólicamente conectadas. 
Tras la relevancia de los términos en conexión con lo espiritual y lo tradicional, constatamos la importancia de los créolismes empleados para tratar de los distintos matices posibles del color de piel de una persona. Estos se revelan significativamente como etiquetas de clase social.

Escogemos mencionar, a este respecto, el adjetivo "chabin(e)": así se denomina en el Caribe francófono a las personas negras de tez más clara por caprichos de la genética, pero descendientes de dos padres oscuros (Condé, 1999, 32).

No muy lejos, se observa cómo el universo masculino emerge en estrechísima relación con el ámbito de la actividad pública y económica: los oficios. A su vez, ésta comparte elementos con la categoría de los insultos y juramentos, arraigado cliché del comportamiento varonil en las sociedades patriarcales. Sirva de ejemplo "boko / bocono": mago, brujo, adivino (Condé, 1989, 200; Condé, 1992, 132 y ss.).

Para terminar, especialmente interesantes, a pesar de su menor frecuencia de aparición, nos resultan los créolismes relacionados con el vestuario y los accesorios en general; y con el vestuario y los accesorios femeninos, domésticos y de la infancia en particular.

En ese sentido, evocaremos, a modo de cierre, un elemento básico en el atuendo de la mujer antillana: el "madras". Es una tela estampada de cuadros de vivos colores o bien lisa, cuando se trata de mostrar el luto y sobrellevar un duelo (Condé, 1989, 58; Condé, 2013, 56), de seda y algodón. Por extensión, se llama así a la pañoleta de este material con la cual acostumbran las mujeres criollas a cubrirse la cabeza o fajarse los riñones durante el trabajo.

Escribir en Maryse Condé, si se nos permite la metáfora, significa precisamente tejer un madrás de compleja urdimbre, donde se anudan hilos, técnicas y materiales de muy diversas procedencias.

En los últimos años, de hecho, Condé afirma haber superado definitivamente el forzado "clivage français-créole" en su escritura e intentar (d)escribir, más que nada, el mundo en "la langue 
de mon temps [...]. Ma langue est une langue qui intègre tous les apports, de l'anglais, un peu d'espagnol, tout ce qui vient..." (Ali Benali, 2009, 59).

Pensamos que lo créole, de este modo, ha de entenderse en la obra condeana como sustrato de mixtura creativa y matriz de hibridación diferencial por excelencia: como abertura tolerante y curiosa a una realidad plural; a la riqueza de la alteridad, la otredad y la diferencia reivindicadas como única bandera posible.

\section{Referencias bibliográficas}

Ali Benali, Z. et alii (2009) "Le rire créole", en Littérature, París, Armand Colin, 2, 13-23.

Alonso Moreno, M.A. (2018) Negritud, sororidad y memoria: poéticas y politicas de la diferencia en la narrativa de Maryse Condé, Dolores Picazo (dir.), Madrid, Universidad Complutense de Madrid, Facultad de Filología.

André, J. (1981) Caraibales, études sur la littérature antillaise, París, L'Harmattan.

Barbotin, M. y Tourneaux, H. (1990) Dictionnaire pratique du créole de Guadeloupe, suivi d'un index français-créole, París, Éditions Karthala.

Barbotin, M. (1995) Dictionnaire du créole de Marie-Galante, Hamburg, Buske.

Bebel-Gisler, D. (1978) Kék prinsip pour ékri Kreyol, París, CNRS.

Belaise, M. (2006) Le discours éthique de la langue proverbiale créole: analyse prolégoménique d'une manière d'être au monde, Publibook, EPU, París.

Bernabé, J. et alii (1993) Éloge de la créolité, París, Éditions Gallimard.

Chaudenson, R. (1979) Les créoles français, París, Nathan.

Condé, M. (1986) Moi, Tituba sorcière, noire de Salem, París, Mercure de France.

Condé, M. (1987) La Vie scélérate, París, Seghers.

Condé, M. (1991) Haïti chérie, París, Bayard Presse. 
Condé, M. (1991) Hugo le Terrible, París, Éditions Sépia.

Condé, M. (1992) Les derniers rois mages, París, Mercure de France.

Condé, M. (1993) La Colonie du nouveau monde, París, Robert Laffont.

Condé, M. (1997a) Desirada, París, Robert Laffont.

Condé, M. (1999) Le cœur à rire et à pleurer. Contes vrais de mon enfance, París, Robert Laffont.

Condé, M. (2006) Victoire, les saveurs et les mots, París, Mercure de France.

Condé, M. (2012) La Vie sans fards, París, JCLattès.

Condé, M. (2013) La Belle et la Bête. Une version guadeloupéene, París, Larousse.

Cremades Cano, I. (2014) Oralidad e identidad femenina en la obra narrativa de Maryse Condé, Antonia López Pagán (dir.), Murcia, Universidad de Murcia, Dpto. de Filología Francesa, Románica, Italiana y Árabe

EgA, F. (1989) Le temps des madras, París, Éditions maritimes et d'outre-mer.

Dodo B. (2008) Dictionnaire de gabonismes, París, L'Harmattan.

Ebroin, A. (1977) La cuisine créole, París, L'Harmattan

Federici, S. (2004) Calibán y la bruja. Mujeres, cuerpo y acumulación originaria, Madrid, Traficantes de Sueños.

Glissant, É. (1997b) Le discours antillais, París, Gallimard.

Hearn, L. (2011) La Cuisine créole: A Collection of Culinary Recipes From Leading Chefs and Noted Creole Housewives, Who Have Made New Orleans Famous for Its Cuisine, [1885], Massachussets, Applewood Books.

Georgel, T. (1999) Contes et légendes des Antilles, París, Nathan.

Hearn, L. (1977) Gombo Zhèbes: Little dictionary of Creole proverbs: selected from six Creole dialects, [1885], Massachussets, Applewood Book.

Le BRIs, M. et alii (2007) Pour une littérature-monde en français, París, Gallimard. 
L'Harmattan (1987) 1000 proverbes créoles de la Caraibe francophone, París, L'Harmattan.

Maignan-Claverie, C. (2005) Le métissage dans la littérature des Antilles françaises. Le complexe d'Ariel, París, Karthala.

Maximin, D. (2006) Les fruits du cyclone. Une géopoétique de la Caraibe, París, Seuil.

Monchoachi (1979) Disidans, París, Djok.

Nègre, A. (1985) Antilles et Guyanne à travers leur cuisine, París, L'Harmattan.

ONU (1982) Especies frutales forestales. Fichas técnicas, Roma, ONU (Organización de las Naciones Unidas para la Agricultura y la Alimentación), FAO.

Pagán López, A. (2004): "Le visible et l'invisible: Moi, Tituba sorcière...", en El texto como encrucijada: estudios franceses y francófonos, La Rioja, Universidad de La Rioja, 1, 721-732.

Pampín, M.F. (2011) “Elogio de la diversidad. Acerca del manifiesto de la creolidad de Jean Bernabé, Patrick Chamoiseau y Raphaël Confiant", en Autres modernités, Universidad de Milán, 6, 109-120.

Pinalie, P. (1994) Dictionnaire de proverbes créoles, Fort-deFrance, Désormeaux.

Pinalie, P. (2009) Dictionnaire élémentaire français-créole, París, L'Harmattan.

Pfaff, F. (1996) Conversations with Maryse Condé, Nebraska, University of Nebraska Press.

Pfaff, F. (2016) Nouveaux entretiens avec Maryse Condé, écrivain et témoin de son temps, París, Karthala.

Romaine, S. (1993), Pidgin \& Creole Languages, Londres, Longman.

Roumain, J. (1989), Gouverneurs de la rosée, París, Éditions Messidor.

Schwarz-Bart, S. (1972), Pluie et vent sur Télumée Miracle, París, Éditions du Seuil.

Talahite-Moodley, A. et alii (2007) Problématiques identitaires et discours de l'exil dans les littératures francophones, Ottawa, Presses de l'Université d'Ottawa. 